\title{
Equal Access to Justice in a Rural Western State
}

\author{
Monte Miller
}

\begin{abstract}
Twenty threeinmatesfrom a rural state penitentiary with mental retardation participated in a study on the differential treatment of persons with mental retardation by the criminal justice system. After obtaining informed consent, the inmates were screened for appropriateness for the study using the PPVT-R, a proxy test for IQ. The inmates were interviewed to obtain a social history and given the CAST-MR, an instrument that measures the competency of a person with mental retardation to stand trial. Results suggest partici pants may not have been competent to stand trial, learned most of what theyknew about thecriminal justicesystem while incarcerated, and had difficulty with interpersonal conflict and conflict with authority. The combination of these factors suggests that dients in thestudy may have been vulnerableto being coerced into confessing to crimes they did not commit. The presence of an advocate during criminal justice system encounters may benefit persons with mental retardation.
\end{abstract}

Keywords: Disabilities, mental retardation, rural, social justice, advocacy, criminal justice

T his article discusses one portion of a larger interdisciplinary study conducted in a rural Western state. The study's purpose was to determine whether persons with mental retardation understood the adjudication process. The study was exploratory in nature and sought to address the question: Do persons with mental retardation understand the adjudication process? Other concerns that were related to the initial question included the treatment of persons with mental retardation while interacting with the criminal justice system. Persons with mental retardation may be vulnerable to verbal, physical, and sexual assault during their encounter with the criminal justice system. The larger study included men and women from several correctional settings; however, this article investigates the experiences of men with mental retardation who were serving time in a state prison.

Adjudication is defined as the ability to hear and settle a case by judicial procedure (American Heritage Dictionary, 2000). The adjudication process, for purposes of this paper, includes this definition and the various stages of

Monte Miller is an Assistant Professor, Division of Social Work, University of Wyoming, Laramie, WY 82071. 
the process including initial questioning, arrest, interrogation, arraignment, trial, and sentencing.

Persons with mental retardation are over-represented in correctional facilities such as prisons, jails, and detention centers. Although persons with mental retardation represent between $1 \%$ and $2 \%$ of the general population, persons with mental retardation represent as much as 30\% of the population in correctional facilities (Conley, Luckasson \& Bouthilet, 1992; Petersilia, 1997). Ellis and Luckasson (1985) state that the criminal justice system has been and continues to be a place where persons with mental retardation are warehoused simply because society does not know what else to do with them. Despite societal progress indicated by legislation such as the Americans with Disabilities Act (ADA, 1990), the efforts of disability organizations, self-advocacy by persons with mental retardation, and media coverage of injustices towards persons with mental retardation, disproportionate numbers of persons with mental retardation in the criminal justice system persist in rural and urban environments (Everington \& Fulero, 1999). The problem is pervasive and complex.

\section{LITERATURE REVEW}

A review of the literature reveals a complex, systematic manner in which people with mental retardation become enmeshed in the criminal justice system. An initial concern is the definition of mental retardation. Although the disproportionate incarceration of people with mental retardation continues, there has been recent disagreement about defining mental retardation in the field of disability studies (Luckasson, 2000). A generally accepted definition is that persons with mental retardation have an IQ of less than 70, childlike thinking qualities, and problems adapting to new situations (AAM R, 1992; APA, 1994). It is worth noting that persons with IQ scores over the 70-point cutoff, such as a person with a score of 80 , may have low cognitive functioning. Such a person may have many of the same difficulties as persons with mental retardation even though he or she lacks the "advantage" of having a defined disability. People in this category are also vulnerable and may "fall through the cracks" of the judicial system.

Persons with mental retardation have several characteristics that put them at risk for abuse or mistreatment while interacting with the criminal justice system (Keyes, Edwards \& Perske, 1997). First, and perhaps most obviously, persons with mental retardation function at lower levels, both adaptively and intellectually, compared to persons without mental retardation. Second, persons with mental retardation can be impulsive, which can result in their committing acts that those without mental retardation refrain from committing. Finally, persons with mental retardation often become easily frustrated, exhibit a desire to please persons in authority such as law enforcement officers, and acquiesce to the wishes of individuals whom they perceive to be in positions of authority (Conley, Luckasson \& Bouthilet, 1992; Everington \& Fulero, 1999; Keyes, Edwards \& Perske, 1997). While persons with mental retardation are certainly individuals and have individual characteristics, the previously listed tendencies are prevalent in the literature.

The combination of these characteristics can lead to unfavorable outcomes during the initial encounter with law enforcement personnel during interroga- 
tion, arraignment, and adjudication, while serving time in a correctional facility, and after release. Persons with mental retardation are less likely to question lengthy interrogations, be susceptible to being led by an interrogator, and are likely to confess in order to please persons in authority (Petersilia, 1997). Persons with mental retardation are vulnerable at all points of encounter with the criminal justice system and are more at risk for sexual and physical abuse once in the correctional system (Pelka, 1997). Finally, often, there is no distinction made between persons with mental retardation and persons without mental retardation during probation or parole proceedings (Pelka, 1997; Petersilia, 1997). Thus, persons with mental retardation are released without a plan for supports and are reincarcerated at a higher rate than persons without mental retardation (Pelka, 1997; Petersilia, 1997). In a rural environment where many people know each other, this has the potential to play out in several ways. If the rural community perceives the person as a criminal, the chances of a lack of supports and reincarceration are greater. Conversely, if the service providers in a rural community utilize their familiarity with the person, a system of supports may be developed that can reduce the chances for reincarceration.

The study was conducted to explore the experiences of male inmates with mental retardation who were al ready incarcerated in a rural state prison and increase the awareness of the criminal justice system to the unique needs of persons with mental retardation. Persons with mental retardation are entitled to special accommodations by the Americans with Disabilities Act (ADA) during the adjudication process and while in correctional facilities (Petersilia, 1997). This study was specifically designed to determine whether the inmates understood the adjudication process.

\section{METHOD}

The research team consisted of a project coordinator, a representative from the state's Division of Developmental Disabilities, a psychologist with a doctorate in law (J.D.), a psychology professor, a social work professor, and a researcher from a multidisciplinary university agency. The project was interdisciplinary and collaborative across many organizational and agency boundaries.

The Department of Corrections (DOC) played a crucial role in the research study. First, the DOC conducted a file review of inmates in the state prison system to identify those with possible IQs of 80 or below. The DOC selected inmates with possible IQ scores of 80 or below, because the tests administered by the DOC were questionable in some cases. By raising the threshold for selection to 80 , the research team sought to include as many appropriate inmates as possible in the study and ensure a sufficient pool of subjects for the research project. Then, the DOC asked these inmates for their initial consent to participate in this project. After obtaining the inmates' consent, the DOC allowed the research team to access the inmates' files.

The DOC identified 65 men out of a total state population of 944 male inmates. This constitutes $7 \%$ of the male inmate population, indicating that the percentage of inmates with mental retardation in the state prison was approximately three times greater than the percentage of persons with mental retardation in the 
state's general population. Seven of the men chose not to participate in the study. Thirteen men could not participate, because they were in segregation for disciplinary problems or they incarcerated in another state due to overcrowding problems. The number of potential participants was reduced to 45.

The research team then examined the 45 files of the inmates who agreed to participate in the study. There were numerous problems with the files of the remaining 45 potential subjects. IQ scores used by the DOC were problematic, despite the willingness of the DOC to share the inmate files. Some files contained an IQ score but no information about which IQ test was used. Other files contained IQ scores from tests that were no longer considered valid. Some of the files contained no IQ score but indicated that the inmate had low cognitive functioning or possible mental retardation. Due to time and budget constraints, the research team used purposive sampling to select 23 inmates for the study. These 23 inmates either had no IQ score $(n=6)$ or lower IQ scores $(n=17)$ than other potential subjects from the original pool of $45 \mathrm{inmates}$. The rationale for this purposive selection was that inmates with no IQ scores or low IQ scores were likely to have Iow IQ scores and, thus, be at risk for having not understood their adjudication process. The Peabody Picture Vocabulary Test-Revised (PPVT-R) was used as a proxy test to assess these inmates' IQ later in the study (Dunn \& Dunn, 1981).

After the research team reviewed the files of the 23 inmates, the DOC arranged a time and place for individual interviews with each inmate. Each inmate met with an interviewer who administered the Competency Assessment for Standing Trial for Defendants with Mental Retardation (CAST-MR). In an attempt to assist persons with mental retardation as they interacted with the criminal justice system, Everington and Luckasson (1992) developed the Competency Assessment for Standing Trial for Defendants with Mental Retardation (CAST-MR). The CASTMR was initially tested for reliability and validity by Everington (1990) and again by Everington and Dunn (1995). Both studies showed the test to be a reliable and valid measure of a person with mental retardation's competency to stand trial with reliability and validity values of .80 or greater. Although the CAST-MR may assist some persons with mental retardation, there is concern that persons with low cognitive functioning may, in fact, score as competent to stand trial and yet not understand the adjudication process (Everington \& Dunn, 1995).

The CAST-MR is administered through interview. It consists of three sections. Section I is Knowledge of Basic Legal Concepts. Section II is Skills to Assist Defense (client-attorney relationship). Section III is Understanding of Case Events. Sections I and II consist of multiple choice questions for which only one answer is correct. Section I contains 25 questions and Section II contains 15 questions. Each question is worth one point, making the maximum score on Section I 25 points and the maximum score on Section II 15 points. Section III consists of 10 open-ended questions that are scored 0,5 , or 1.0 based on the sophistication of the response. The maximum possible score on Section III is 10 points. The highest possibletotal score on the CAST-MR is 50. Clinical cut off scores for determining competency to stand trial are 14 points for Section I, 10 points for Section II, 7 points for Section III, and 30 points for the total CAST-MR (Everington \& Dunn, 1995). 
The interviewer also conducted a social history interview with the inmate, including open-ended questions about the inmate's family, education, employment, and memories about his most recent adjudication. The inmate was asked questions such as: Can you please tell me about your family? The social history interview served two purposes. It provided the interviewer with information about the inmate's cognitive and language abilities as well as documenting sources of support for the inmate such as family, friends, educators, and employers. The interviewer also asked the inmate to describe his last adjudication in as much detail as possible. This provided additional information to supplement the CAST-MR scores. In some cases, the interviewer obtained permission from the inmate to contact other people such as teachers or friends in order to clarify the information provided by the inmate.

Finally, the interviewer administered the Peabody Picture Vocabulary Test-Revised (PPVT-R) (Dunn \& Dunn, 1981). The PPVT-R is a test of receptive language functioning and is highly correlated with IQ. It was used as a measure to assess the validity of the DOC IQ scores in the inmates' files. The PPVT-R score was used as a proxy score for IQ in cases where the DOC could not provide an IQ score.

\section{Rationale for Multiple Research Methods}

The CAST-MR was given to determine the competency level of the inmate to understand the adjudication process and to assess the practicality of using the CAST-M R as a screening test to assist criminal justice system personnel in identifying persons with mental retardation early in the adjudication process. The social history interview was used to further assess the inmate's cognitive and language abilities and obtain information about the services and supports that the inmate had prior to incarceration. The PPVT-R was administered as a comparative measure to the IQ scores in the inmates' files or, in the case of inmates with no IQ score in their files, to establish a baseline measure of cognitive functioning to serve as a screening instrument to identify potential study participants.

\section{RESULTS}

\section{Sample Characteristics}

The inmates' mean age was 39.5 ( $s d=15.3$ ) years of age. Forty percent of the inmates were from traditional ethnic minority groups including four African Americans, three Native Americans, and two Hispanics. The remaining inmates $(n=14)$ were Caucasian. Fifty two percent $(n=12)$ of the inmates had a history of special education involvement. Seventeen percent $(n=4)$ had received a GED. Only one inmate had a high school diploma. The types of crimes for which the subjects were imprisoned included property related (43\%), person-related (35\%), and drug related (17\%). These percentages do not cumulatively equal $100 \%$, because some of the inmates were imprisoned for multiple types of crimes.

\section{IQ and PPVT-R Scores}

The IQ scores obtained from DOC files $(m=73.3, \mathrm{sd}=4.6, n=17)$ were comparable to the PPVT-R scores $(m=72.9, s d=13.7, n=23)$ for inmates who had an IQ score in their DOC files. This would seem to indicate the possible presence of mild men- 
tal retardation or low cognitive functioning. An individual has mild mental retardation if his or her IQ score ranges from approximately 50-55 to approximately 70 and does not demonstrate adaptive behavior towards his or her environment (AAMR, 1992; APA, 1994). As explained by Luckasson (2000), the definition of mental retardation is questionable but the standards provide a guideline.

\section{CAST-MR Scores}

Scoring for the CAST-MR includes a total score and scores for the three sections. The mean total CAST-M R score for the sample was 45.1 ( $\mathrm{sd}=5.25$ ) out of a possible 50 total points. The mean score for Section I: Knowledge of Basic Legal Concepts was 23.6 ( $\mathrm{sd}=2.98$ ) out of 25 possible points. The mean score for Section II: Skills to Assist Defense (client/attorney relationship) was 12.2 $(s d=2.32)$ out of 15 possible points. The mean score for Section III: Understanding of Case Events was 9.3 ( $\mathrm{sd}=2.98$ ) out of 10 possible points. These means were comparable to scores for the original norming study for the CASTMR (Everington, 1990). According to the CAST-MR scores, all of the inmates should have been competent to stand trial when this study was conducted.

Item analyses revealed six questions in Section II: Skills to Assist Defense (client-attorney relationship) that had high error rates. A high error rate was operationalized as $20 \%$ or greater. Errors occurred when the inmate selected the wrong answer from the multiple-choice responses that were provided. For example, Item 35 states, "Let's pretend that you are in court and the prosecutor tells a lie about you and it makes you really mad! What would you do?" The responses for Item 35 are: a) "tell the prosecutor off," b) "tell your lawyer," and c) "refuse to answer anymore questions." The correct response for Item 35 was b) "tell your lawyer." Sixty five percent $(n=15)$ of respondents checked b): "tell your lawyer." Thirty five percent $(n=8)$ of the respondents checked response $c)$ : "refuse to answer any more questions." Thus, Item 35 had an error rate of 35\%. Items 28, 31, 32, 35, 38, and 40 had error rates of 20 to 39\%. These items are in Appendix A. The error rates for the other items in Section II of the CAST-MR were $11 \%$ or less.

Items with high error rates described interpersonal conflict situations involving the inmate and the defense attorney, judge, or prosecuting attorney. The items with high error rates also described conflict with a person in authority. Returning to Item 35, the correct answer was b): "tell your lawyer." All of the inmates $(n=8)$ who responded incorrectly to Item 35 chose the passive response of "refuse to answer any questions." None of them chose the confrontational response of "tell the prosecutor off." For inmates who responded incorrectly, the passive answer accounted for $100 \%$ of the errors.

Item 38 demonstrates a similar pattern. Item 38 states, "What if you are in the courtroom and you hear your lawyer and judge talking about you and you do not understand what they are saying. What would you do?" The responses for Item 38 are: a) "pretend you understand," b) "ask you lawyer about it," and c) "demand that they talk to you." The correct response, b) "ask you lawyer about it," was checked by $65 \%(n=15)$ of the inmates. Twenty six percent $(n=6)$ of the inmates who responded incorrectly to Item 38 checked response a) "pretend 
you understand," while only 2 or $9 \%$ selected response, c) "demand that they talk to you." Once again, the majority of the inmates who responded incorrectly to Item 38 ( $n=6$, or $75 \%$ ) chose a passive response instead of a confrontational response.

\section{Correlations}

Correlational analyses revealed no significant correlation between IQ and total CAST-MR score $(r=23, p>10)$. This result was unexpected, as previous studies have shown relationships between IQ scores and CAST-MR scores (Everington, 1990; Everington \& Dunn, 1995). There was a correlation of $.52(p<05)$ between the CAST-M R and PPVT-R scores. CAST-MR scores are usually related to PPVT-R scores. Both competency to stand trial and receptive language ability were expected to be related.

\section{Social History Results}

The data from the social history interviews were analyzed using content analysis (Rubin \& Babbie, 2000). The research team used latent content analysis to look for consistent concepts in the transcripts. The interviews were audio recorded. Members of the research team listened to and rated tapes from the first three inmates to check for inter-rater reliability. Although the inmates scored well as a group on the CAST-MR, the interview data obtained during the social history portion of the research indicated the possibility of a lack of competency. While the inmates were willing to participate in the research and eager to discuss their lives, they had problems providing details about their adjudication process. They seemed to have difficulty expressing themselves, and their confusion and limited ability to respond suggested the possible presence of a cognitive impairment such as mental retardation or low cognitive functioning. As an example from the transcripts, one inmate commented:

Hetold the cop that I took a stereo....and I asked my lawyer to go back over to ask the court, and to have the cops go back over there and check this out...

Thejudge. ...that there wasn't, ah, that hecouldn't order that to bedone. So they, he, judge. .. the one sends to meup hereand I was trying to fight it but every timel do, I get, I get turned around on it

The inmates did provide some insight into their understanding of the adjudication process beyond the information that was obtained from the CAST-MR. More than half of the inmates $(n=14,61 \%)$ indicated that they had learned what they knew about how the criminal justice system works in prison rather than from their attorney or judge during the adjudication process. For instance, one inmate said:

Theattorney spent a little bit of time with me, uh, explaining... but at that timel really didn't .... I didn't really...I understand thelaw a lot better now than when I did then. I didn't really understand the law a wholelot then. And, well, I knew there was a right and wrong, but as far as the law goes, that's about it. 
Although the ability to learn about the adjudication process seemed to be present, the timing of the learning was unfortunate. Many inmates $(n=11$, 48\%) mentioned taking actions such as signing confessions, accepting plea bargains, or providing self-incriminating information. Some inmates $(n=8$, $35 \%$ ) reported a fear or dislike of their attorney, said they felt pressured into accepting plea agreements, and remembered being told that they should "take the deal." These situations all involve interpersonal conflict or conflict with another person and conflict with a person in authority. The combination of interpersonal conflict and conflict with a person in authority may set up situations wherein persons with mental retardation are likely to acquiesce to the demands of criminal justice system personnel.

\section{DISCUSSION}

\section{Limitations}

Before discussing the study's findings, there are several limitations that must be addressed. First, this study utilized a small, purposive sample in a rural Western state. The results of this small study are not generalizable. The data obtained from a rural sample may be different from data obtained from an urban sample. The small sample size may have skewed the data. Second, despite the DOC's willingness to assist with the study, IQ scores in the DOC files were of questionable validity. Some IQ scores were not referenced to an IQ test, while others used tests that are no longer valid. Many of the files did not indicate who administered the IQ test to the inmate, so the qualifications of the test administrator may have effected the scores. Taking all these factors into consideration, the validity of the IQ scores is questionable. Finally, this was an initial exploratory study. This research process was new for the research team, the DOC staff, and the inmates who participated. It is possible that the inmate interview process, including administration of the CAST-MR, the PPVT-R, and the social history interview, may have varied as the research team became more familiar with the interview process.

\section{IQ and PPVT-R Scores}

Despite these limitations, the findings of this study raise some questions. Both the IQ and the PPVT-R tests had similar means for the sample, which suggested that the sample may have had mental retardation or low cognitive functioning. This group of inmates scored slightly above the IQ cutoff score of 70 for mental retardation. Their scores on the PPVT-R were indicative of low cognitive functioning. Many of them provided accounts of not being able to display adaptive behavior, as demonstrated by excerpts from the transcripts and information in their case records. This combination of IQ and PPVT-R scores, along with a lack of adaptive behavior, indicate that this group had some level of mental retardation or at least low cognitive functioning.

\section{CAST-MR Scores}

With regard to the CAST-MR test, as a group, the inmates' scores indicated that they would have been competent to stand trial at the time of this study. Their competency when they actually stood trial is unknown. Their mean 
total score on the CAST-MR of $45.1(s d=5.25)$ is indicative of competency according to the CAST-MR (Dunn \& Dunn, 1981; Everington, 1990). Their scores on the subsections would also suggest that they were competent in Knowledge of Basic Legal Concepts (Section I), Skills to Assist Defense (Section II), and Understanding of Case Events (Section III).

\section{CAST-MR High Error Rate Items}

The error rates on several CAST-M R items in Section II were quite high, ranging from $39 \%$ to $22 \%$ and are presented in Table 1.

\begin{tabular}{|l|c|}
\hline Table 1: High Error Rateltems in CAST-MR Section II: Skills to Assist Defense \\
\hline CAST MR Section II Item & Error Rate \\
\hline $\begin{array}{l}\text { Item 40: What if you and your lawyer decide that you are going to } \\
\text { say certain things when you are on the stand; then later on, you } \\
\text { decide to change your story. What would you do? }\end{array}$ & $39 \%$ \\
\hline $\begin{array}{l}\text { Item 38: What if you are in the courtroom and you hear your lawyer } \\
\text { and judge talking about you and you don't understand what they are } \\
\text { saying. What would you do? }\end{array}$ & $35 \%$ \\
\hline $\begin{array}{l}\text { Item 35: Let's pretend you are in court and the prosecutor tells a lie } \\
\text { about you and it makes you really mad! (emphasize) } \\
\text { What would you do? }\end{array}$ & $35 \%$ \\
\hline $\begin{array}{l}\text { Item 31: What if your lawyer asks you to do something you don't want } \\
\text { to do, like getting a haircut? What would you do? }\end{array}$ & $35 \%$ \\
\hline $\begin{array}{l}\text { Item 32: Lets pretend that you are in court and your lawyer asks you } \\
\text { to tell a short part (emphasize) of your story. For example, he asks you } \\
\text { to tell the court what you said to the police when they arrested you. } \\
\text { What would you do? }\end{array}$ & $22 \%$ \\
\hline $\begin{array}{l}\text { Item 28: What if you are in jail and another prisoner tells you it's OK } \\
\text { to tell him the whole story because he won't tell anyone. What would } \\
\text { you do? }\end{array}$ & $22 \%$ \\
\hline
\end{tabular}

Error rates were $39 \%$ for Item $40,35 \%$ for Items 38,35 , and 31 , and $22 \%$ for Items 32 and 28. All of these items describe interpersonal conflict situations and conflict with authority with persons such as a defense attorney, judge, or prosecuting attorney. Item 28 does not involve persons such as a defense attorney, judge, or prosecuting attorney, but it does involve conflict, as defendants are usually told to not discuss their case with other prisoners. These results are consistent with the inclination of persons with mental retardation to exhibit a desire to please persons in authority and acquiesce to the wishes of individuals whom they perceive to be in positions of authority (Conley, Luckasson \& Bouthilet, 1992; Everington \& Fulero, 1999; Keyes, Edwards \& Perske, 1997).

For instance, Item 38 reads: "What if you are in the courtroom and you hear your lawyer and the judge talking about you and you don't understand what they are saying." The correct answer is b) "ask your lawyer to talk about it later." Response c) "demand that they talk to you," is not acceptable during a court proceeding due to the risk of being placed in contempt of court. Also, 
and perhaps more importantly, response c) is not a likely response for someone who doesn't understand the judicial process and is passive in order to avoid interpersonal conflict or conflict with authority. Taking the avoidance of conflict into account, the error rate of $35 \%$ for Item 38 is not surprising.

The interview comments seemed to support the desire to avoid situations of interpersonal conflict or conflict with authority. Approximately half $(n=11)$ of the inmates made references to feeling coerced or pressured into accepting a plea agreement. Being told that they should "take the deal" was a recurrent theme in the interviews with the inmates. Some inmates expressed dislike or even fear of their attorney.

\section{Social History Results}

Although the study's findings are far from conclusive, the implication is that while the CAST-M R may have correctly indicated the inmates were competent to stand trial at the time of the study, they may not have been competent to stand trial at the time of their actual trial and during theadjudication process. The use of the CAST-MR and the social history interviews provided a more comprehensive assessment of the inmates' ability to understand the adjudication process than using just the CAST-MR or just the social history interview. The social history also helped to better describe issues such as conflict with attorneys or prosecutors and situations in which persons with mental retardation are coerced into accepting plea agreements or "deals."

\section{CONCLUSION}

Despite several limitations, this study provided some insight into areas of concern for persons with mental retardation who are interacting with the criminal justice system. The first concern is how to define mental retardation. It seems that there is some consensus that more than an IQ test is required and adaptive behavior should be considered (Luckasson, 2000). However, beyond these areas of agreement, the definition of mental retardation becomes nebulous at best. Despite this lack of consensus, it would seem the lack of adaptive behavior was problematic for the inmates in this study. Some inmates who may not be classified as having mental retardation because their IQ score is above the cutoff score of 70, may still have problems demonstrating appropriate and adaptive behavior during the adjudication process. These inmates with low cognitive functioning are also at risk when interacting with the criminal justice system. In fact, they may be at greater risk, because the Americans with Disabilities Act does not protect them because, technically, they do not have a disability.

Although previous studies have discussed differential impact for persons with mental retardation when they interact with the criminal justice system, currently, there are no standards for how to identify persons with mental retardation as they enter the system. The use of an instrument such as the CAST-MR may be a starting point for identifying the competency of persons with mental retardation to stand trial. However, standing trial is a point at which the person has progressed past several steps into the adjudication process. Questions remain concerning how to identify persons with mental retardation or low cognitive functioning as they enter the criminal justicesystem at points such as initial question- 
ing, arrest, interrogation, arraignment, standing trial, and sentencing. Is it feasible to develop instruments or protocols to identify persons from this population at the numerous points of contact with the criminal justice system? Yet another, and perhaps more important question is, after criminal justice system personnel identify persons with mental retardation, how can the criminal justice system provide accommodations for them?

Setting aside the definition, identification, and accommodation issues, the findings of this study seem to indicate that the inmates may not have been competent to stand trial at the time of their trial. Many participants $(n=14)$ reported learning about the criminal justice system while in prison. While it is encouraging that these men could learn more about the system, the timing of the learning is not in their best interests. The situation certainly does not advance social justice, as these men learned about the criminal justice system after they had been imprisoned.

The issues of conflict, both interpersonal and with authority, were recurrent themes in this study. The literature review illustrated that persons with mental retardation are prone to trying to please persons in authority and may acquiesce to the wishes of persons in authority in order to do so. The high error rates on the items that involved interpersonal conflict and conflict with authority in Section II of the CAST-MR, Skills to Assist Defense support this perspective. The social history data also supported the concepts of avoiding interpersonal and authority related conflict. The tendency to avoid conflict of multiple types places persons with mental retardation interacting with the criminal justice system in a very vulnerable situation.

Department of Corrections personnel were very cooperative in facilitating the conduct of this research. However, despite their cooperation, it is not difficult to imagine a situation in which a person with mental retardation might acquiesce and confess to a crime he or she did not commit in order to avoid interpersonal conflict and conflict with authority. While members of the law enforcement community are ethical and attempt to uphold justice, it is feasible that not recognizing that a person has mental retardation, combined with standard interrogation techniques, might in fact result in coerced and inaccurate confessions to crimes. Situations such as these put persons with mental retardation and the community at-large at risk by prosecuting innocent citizens and allowing criminals to remain free in the community.

What can social workers in rural environments do to provide support for persons with mental retardation as they interact with the criminal justice system? The role of advocate (Schatz, Jenkins \& Sheafor, 1989) seems to be a logical place to start. A person with mental retardation could benefit greatly from an advocate, especially given that some of the participants in this study expressed dislike or even fear of their own defense attorneys. If persons with mental retardation sometimes fear their own defense attorneys, what level of fear might they have towards police officers, judges, or prosecuting attorneys?

A social worker with knowledge about mental retardation and the adjudication process could be brought into the adjudication process at an early stage, such as 
when criminal justice system personnel think a person who is being questioned or arrested has limited cognitive abilities. In rural areas, the social worker is more likely to know at least some of the criminal justice system personnel , which could be advantageous to the client. Having an advocate early on in the adjudication process could have a very positive impact on the way in which persons with mental retardation interact with the criminal justice system and further the cause of social justice for this population. Social justice for persons with low cognitive functioning could be advanced in the same manner, although it would require additional social work skills at the mezzo and macro level to get recognition for this population. This issue leads to yet another question.

If persons with mental retardation receive an advocate, why shouldn't other populations who are over-represented in the correctional system have an advocate as well? From a social justice perspective, the answer would seem to be that many populations, such as people of color and persons of low socioeconomic status should in fact have advocates when interacting with the criminal justice system. The introduction of an advocate into the adjudication process is an intervention that is within the ability of social workers. The importance of such an advocate cannot be overemphasized as many states continue to use the death penalty on inmates with mental retardation (Olvera, Deaver \& Earnest, 2000; Perske, 1997; Steiker \& Steiker, 1998; Everington \& Fulero, 1999). According to Everington and Fulero (1999), persons with mental retardation represent approximately $11 \%$ of the inmates on death row. Persons with mental retardation are not only a population at risk but also a population at risk of death. The other populations mentioned also face the risk of unjust incarceration or death. As a profession, we must not only acknowledge social injustice, but also pursue interventions that can tip the scales of justice in favor of populations at risk. The cooperation across disciplines and professions, including the Department of Corrections in this rural study, demonstrate that at least in this rural environment collaboration was possible to conduct the study and start the process of advocacy. Such collaboration may be more difficult in urban settings. This is an area in which rural social workers have the opportunity to take the lead on an important social justice issue.

\section{References.}

American Heritage Dictionary. (2000). Boston: Houghton and Mifflin.

American Association on Mental Retardation. (1992). Definitions, classification, and systems of supports. ( $9^{\text {th }}$ ed.). Washington, D.C.: Author.

American Psychological Association. (1994). Diagnostic and Statistical Manual of Mental Disorders, $\left(4^{\text {th }}\right.$ ed., DSM-IV). Washington, D.C.: Author.

Americans with Disabilties Act, (ADA), (1990) 42 ${ }^{\text {nd }}$ USC 12101.

Conley, R., Luckasson, R., \& Bouthilet, G. (1992). The criminal justice system and people with mental retardation. Baltimore: Brookes.

Dunn, L., \& Dunn, L. (1981). The Peabody PictureVocabulary Test-Revised. Circle Pines, MN: American Guidance Service. 
Ellis, J., \& Luckasson, R. (1985). Mentally retarded criminal defendants. GeorgeWashington Law Review, 414, 416-421.

Everington, C. (1990). The Competence Assessment for Standing Trial for Defendants with Mental Retardation (CAST-MR): A validation study. Criminal Justiceand Behavior, 17(2), p 147-168.

Everington, C., \& Dunn, C. (1995). A second validation study of the Competence Assessment for Standing Trial for Defendants with Mental Retardation (CAST-MR). Criminal Justice and Behavior, 22(1), p. 4459.

Everington, C., \& Fulero, S. (1999). Competence to confess: Measuring understanding and suggestibility of defendants with mental retardation. Mental Retardation, 37(3), 212-220.

Everington, C., \& Luckasson, R. (1992). Competence Assessment for Standing Trial for Defendants with Mental Retardation: CAST-MR. Worthington, OH: International Diagnostic Services.

Keyes, D., Edwards, W., \& Perske, R. (1997). People with mental retardation are dying, legally. Mental Retardation, 35(1), 59-63.

Luckasson, R. (2000). Defining Mental Retardation. AAMR News and Notes, 13(5), 1-5.

Olivera, D., Dever, R., \& Earnest, M. (2000). Mental retardation and sentences for murder: Comparison of two recent court cases. Mental Retardation, 38(3), 228-33.

Pelka, F. (1997). Unequal justice: preserving the rights of the mentally retarded in the criminal justice system. The Humanist, (57), 28-32.

Perske, R. (1997). Prisoners with mental disabilities in 1692 Salem and today. Mental Retardation, 35(3), 315-317.

Petersilia, J. (1997). Justice for all? Offenders with Mental Retardation and the California corrections system. Prison Journal, 77(4), 358-380.

Rubin, A., \& Babbie, E. (2000). Research methods for social work $4^{\text {th }}$ ed.). Pacific Grove, CA: Brooks/Cole.

Schatz, M., Jenkins, L., \& Sheafor (1989). Milford redined: A model of generalist and advanced generalist social work. Fort Collins, CO: Colorado State University.

Steiker, C., \& Steiker, J. (1998). Defending categorical exemptions to the death penalty: Reflections on the ABA's resolutions concerning the execution of juveniles and persons with mental retardation. Law and Contemporary Problems, 61(4), 89-104.

\section{Author's Note:}

Address correspondence to: Monte Miller, Ph.D., Division of Social Work, University of Wyoming, P.O. Box 3632, Laramie, Wyoming 82071, USA. E-mail: millerm@uwyo.edu 


\section{Appendix}

\section{CAST-MR Items with High Error Rates; Section II: Skills to Assist Defense}

\section{Error Rate}

40. What if you and your lawyer decide that you are going to $39 \%$ say certain things when you are on the stand; then later on, you decide to change your story. What would you do?
a. say what you want when you are on the stand
b. tell the court to get you a new lawyer
c. *tell your lawyer you would like to change the story

38. What if you are in the courtroom and you hear your lawyer and judge talking about you and you don't understand what they are saying. What would you do?
a. pretend you understand
b. *ask your lawyer about it later
c. demand that they talk to you

35. Let's pretend you are in court and the prosecutor tells a lie about you and it makes you really mad! (emphasize) What would you do?
a. tell the prosecutor off
b. *tell your lawyer
c. refuse to answer more questions

31. What if your lawyer asks you to do something you don't want to do like getting a haircut? What would you do?
a. *tell him you don't want to
b. ignore him and do what you want
c. fire the lawyer on the spot

32. Lets pretend that you are in court and your lawyer asks you to tell a short part (emphasize) of your story. For example, he asks you to tell the court what you said to the police when they arrested you. What would you do?
a. don't say anything about it
b. *tell what you said to the police
c. tell everything that happened

28. What if you are in jail and another prisoner tells you it's

OK to tell him the whole story because he won't tell anyone. What would you do?
a. *tell him you can't tell
b. start a fight with him
c. tell him the story 